\title{
Management of Patients with Asymptomatic and Symptomatic Carotid Artery Disease: Update on Anti-Thrombotic Therapy
}

\author{
Daniele Pastori ${ }^{1}$ John W. Eikelboom ${ }^{2}$ Sonia S. Anand ${ }^{3}$ Manesh Raman Patel ${ }^{4}$ \\ Jean-Francois Tanguay ${ }^{5}$ Jean-Baptiste Ricco ${ }^{6}$ Eike Sebastian Debus ${ }^{7} \quad$ Lucia Mazzolai $^{8}$ \\ Rupert Bauersachs ${ }^{9,10}$ Peter Verhamme ${ }^{11}$ Jackie Bosch ${ }^{12,13}$ Sigrid Nikol ${ }^{14}$ Mark Nehler $^{15}$ \\ Victor Aboyans ${ }^{16,17}$ Francesco Violi ${ }^{1}$
}

${ }^{1}$ I Clinica Medica, Atherothrombosis Centre, Department of Internal Medicine and Medical Specialties, Sapienza University of Rome, Rome, Italy

${ }^{2}$ Department of Medicine, McMaster University, Hamilton, Ontario, Canada

${ }^{3}$ Department of Medicine, Population Health Research Institute, McMaster University, Hamilton Health Sciences, Hamilton, Ontario, Canada

${ }^{4}$ Duke Clinical Research Institute, Duke University Medical Center, Durham, North Carolina, United States

${ }^{5}$ Department of Medicine, Montreal Heart Institute, Université de Montréal, Montreal, Québec, Canada

${ }^{6}$ Department of Clinical Research and Innovation (DRCI), University Hospital of Poitiers, Poitiers, France

7 Department of Vascular Medicine, University Heart Center Hamburg, Hamburg, Germany

${ }^{8}$ Division of Angiology, Lausanne University Hospital, University of Lausanne, Lausanne, Switzerland

${ }^{9}$ Department of Vascular Medicine, Klinikum Darmstadt GmbH, Darmstadt, Germany

Thromb Haemost 2019;119:576-585.
Address for correspondence Francesco Violi, I Clinica Medica, Viale del Policlinico 155, Rome, 00161, Italy

(e-mail: francesco.violi@uniroma1.it).

${ }^{10}$ Center of Thrombosis and Hemostasis, Johannes Gutenberg University Mainz, Mainz, Germany

${ }^{11}$ Department of Cardiovascular Sciences, Center for Molecular and Vascular Biology, University of Leuven, Leuven, Belgium

12 Population Health Research Institute, McMaster University, Hamilton Health Sciences, Hamilton, Ontario, Canada

${ }^{13}$ School of Rehabilitation Science, McMaster University, Hamilton, Ontario, Canada

${ }^{14}$ Department of Clinical and Interventional Angiology, Asklepios Klinik St. Georg, Hamburg, Germany

${ }^{15}$ CPC Research, Aurora, Colorado, United States

${ }^{16}$ Department of Cardiology, Dupuytren University Hospital, 2, Martin Luther King Ave, Limoges, France

17 Research Unit INSERM 1094, Faculté de médecine de Limoges, Limoges, France

Abstract
Keywords
- carotid artery disease
- anti-thrombotic
therapy
- anti-platelet
- anticoagulant
- rivaroxaban
- aspirin

The most common causes of ischaemic stroke are represented by carotid artery atherosclerotic disease (CAAD) and atrial fibrillation. While oral anticoagulants substantially reduce the incidence of thromboembolic stroke ( $<1 \% /$ year), the rate of ischaemic stroke and other cardiovascular disease events in patients with CAAD remains high, ranging from 8.4 to 18.1 events per 100 patient-years. Similar to any other atherosclerotic disease, anti-thrombotic therapies are proposed for CAAD to reduce stroke and other cardiovascular events. The 2017 European Society of Cardiology (ESC)/European Society for Vascular Surgery (ESVS) guidelines recommend for patients with asymptomatic CAAD $\geq 60 \%$ the use of aspirin 75 to $100 \mathrm{mg}$ once daily or clopidogrel $75 \mathrm{mg}$ once daily at the exception of patient at very high bleeding risk. For patients with symptomatic CAAD $\geq 50 \%$, the use of aspirin 75 to $100 \mathrm{mg}$ once daily or clopidogrel $75 \mathrm{mg}$ once daily is recommended. New perspectives for anti-thrombotic therapy for the treatment of patients with CAAD come from the novel dual pathway strategy combining a low-dose anticoagulant (i.e. rivaroxaban) and aspirin that may help reduce longterm ischaemic complications in patients with CAAD. This review summarizes current evidence and recommendations for the anti-thrombotic management of patients with symptomatic or asymptomatic CAAD or those undergoing carotid revascularization. received

October 12, 2018

accepted after revision

December 21, 2018 (c) 2019 Georg Thieme Verlag KG Stuttgart · New York
DOI https://doi.org/

10.1055/s-0039-1678527. ISSN 0340-6245. 


\section{Introduction}

Cardiovascular (CV) disease is one of the most important causes of morbidity and mortality worldwide, with a substantial burden on quality of life, particularly in patients who are left with disabilities after a disabling myocardial infarction (MI) or stroke. ${ }^{1}$ About one-quarter of all ischaemic strokes are cardioembolic in origin, mostly occurring in patients with atrial fibrillation (AF), ${ }^{2}$ and three-fourths are atherothrombotic, including carotid artery atherosclerotic disease (CAAD). ${ }^{3}$

Vitamin K antagonists (VKAs) reduce stroke by approximately $70 \%$ in patients with $\mathrm{AF}^{4}$ The difficulties in managing VKA treatment, and their high associated bleeding risk, prompted the development of the non-VKA oral anticoagulants (NOACs), either thrombin or factor Xa inhibitors, which are at least as effective and safer than VKAs. ${ }^{5}$

Ischaemic stroke in patients with CAAD may result from arterial occlusion or embolization of a thrombus from an unstable carotid plaque to the cerebral vessels. ${ }^{6}$

Anti-thrombotic therapy is the primary treatment for patients with carotid stenosis to reduce the risk of periprocedural and long-term complications. This includes antiplatelet drugs such as aspirin, which irreversibly acetylates COX-1, thereby preventing production of platelet thromboxane $A_{2}$, or $\mathrm{P}_{2} \mathrm{Y}_{12}$ receptor antagonists, which inhibit interaction of adenosine diphosphate with the receptor. ${ }^{7}$ Recent studies evaluated NOAC-based anti-thrombotic regimens combined with anti-platelet therapy. For example, the combination of the factor Xa inhibitor rivaroxaban with aspirin in patients with stable vascular disease, thereby targeting two different anti-thrombotic pathways. ${ }^{8}$

In addition to anti-thrombotic drugs, optimal medical therapy of patients with clinically apparent atherosclerosis should include smoking cessation, and use of anti-hypertensive agents and lipid-lowering drugs, ${ }^{9}$ as burden and progression of CAAD is strictly dependent on concomitant atherosclerotic risk factors such as smoking, hypertension, diabetes or dyslipidaemia. ${ }^{10}$

In this narrative review, we summarize the management of CAAD with a focus on anti-thrombotic therapy in patients with asymptomatic and symptomatic disease.

\section{Epidemiology and Screening of CAAD}

The prevalence of CAAD depends greatly on the population studied and the stenosis threshold used for inclusion. ${ }^{11}$ In the Tromsø Study, which included subjects from the general population $>50$ years, the prevalence of carotid stenosis of $\geq 35 \%$ was $3.8 \%$ among men and $2.7 \%$ among women. ${ }^{12}$ In the Offspring Cohort of the Framingham Heart Study, which included 3,173 subjects (mean age: 55 years), the prevalence of carotid stenosis of $\geq 25 \%$ was $24 \%$ in men and $14 \%$ in women. ${ }^{13}$ The prevalence of CAAD was shown to greatly increase in patients 65 years and older in the Cardiovascular Health Study, with carotid plaques observed in $75 \%$ of men and $62 \%$ of women in this age group. ${ }^{14}$

Screening for asymptomatic CAAD in the general population is not recommended by the U.S. Preventive Services Task
Force, given the lack of randomized trials showing the value of the screening. ${ }^{15}$ An evidence-based guideline recommended to screen for asymptomatic CAAD patients with symptomatic peripheral artery disease (PAD), coronary artery disease or atherosclerotic aortic aneurysm. ${ }^{16}$ Furthermore, patients with two or more of the following CV risk factors, including arterial hypertension, hyperlipidaemia, smoking, a family history of early-onset atherosclerotic disease in a first-degree relative or a family history of ischaemic stroke, could be screened for the presence of asymptomatic CAAD. ${ }^{16}$

Given the very slow rate of intima-media thickness (IMT) growing ( $>0.01 \mathrm{~mm} /$ year) in the general population, ${ }^{11}$ it is not reasonable to repeat carotid Doppler ultrasound in patients with a first normal/mildly increased IMT. Conversely, it is reasonable to repeat duplex ultrasonography annually to assess the progression or regression of CAAD and response to therapeutic interventions in patients with carotid stenosis of $>50 \%{ }^{17}$

Patients with CAAD are usually classified as 'asymptomatic' and 'symptomatic' (i.e. acute signs or symptoms of cerebral or ocular ischaemia in the previous 6 months). In the general population, the prevalence of asymptomatic moderate CAAD (stenosis $\geq 50 \%$ ) in subjects aged $\geq 70$ years was $12.5 \%$ in men and $6.9 \%$ in women, and the overall prevalence of severe CAAD (stenosis $\geq 70 \%$ ) was $1.7 \%{ }^{18}$ A pooled analysis of 23,706 individuals from four population-based cohort studies showed that factors associated with CAAD ( $>50 \%$ or $>70 \%$ stenosis) were age, sex, prior vascular disease, systolic and diastolic blood pressure, total cholesterol/high-density lipoprotein ratio, diabetes mellitus and smoking status. ${ }^{19}$

\section{Risk of Cardiovascular and Cerebrovascular Events in Patients with CAAD}

When a significant carotid plaque is detected, as defined by a focal narrowing of the carotid artery of $\geq 50 \%$ or an increased carotid IMT of $\geq 1.5 \mathrm{~mm}$, a patient is categorized as 'high risk' for CV disease. ${ }^{20}$

The risk of ischaemic stroke is dependent on clinical presentation and is higher in patients with symptomatic carotid artery stenosis compared with asymptomatic patients. In patients with asymptomatic CAAD (stenosis $>50 \%$ ), the annual rate of stroke is $2 \%$ and the rate of coronary events is $7 \% .^{21,22}$ In patients with symptomatic carotid stenosis who are treated with medical therapy only, the risk of CV events is higher, ranging from 8.4 to 18.1 events per 100 patientyears. ${ }^{9,23}$ Moreover, in a registry of patients with near occlusion carotid artery stenosis treated medically after a first ischaemic stroke, the incidence of recurrent ipsilateral stroke/transient ischaemic attack is $10.6 \%$ at 90 days. ${ }^{24}$ This high risk of further events in the 14 days after the initial event was demonstrated in a study of 377 patients with symptomatic carotid stenosis of 50 to $99 \%$ awaiting elective revascularization. ${ }^{25}$ Current guidelines recommend that, when revascularization is considered appropriate in symptomatic patients with $>50 \%$ stenosis, this should be performed as soon as possible, preferably within 14 days of symptom onset. ${ }^{26}$ 
This risk is even higher in patients with CAAD who have clinically overt atherosclerosis in other vascular beds, such as coronary artery disease or PAD in the lower limbs. ${ }^{27}$

Finally, in patients undergoing carotid surgery, the 4-year rates of stroke and death were 8.0 and $6.4 \%$ for symptomatic patients and 4.5 and $2.7 \%$ for asymptomatic patients, respectively ${ }^{28}$

However, when evaluating the risk of CV and cerebrovascular events in a patient with CAAD, it should be taken into consideration not only the degree of carotid stenosis, but also the presence of cardiometabolic risk factors frequently associated with CAAD. ${ }^{29}$ Patients with asymptomatic CAAD and additional uncontrolled $\mathrm{CV}$ risk factors are at increased risk for $\mathrm{CV}$ events. For instance, patients with cardiometabolic diseases, such as AF, diabetes mellitus, metabolic syndrome and co-existence of CAAD, are at higher risk of ischaemic events as compared with patients without CAAD ( - Table 1)..$^{20}$

\section{Carotid Revascularization}

Determining whether patients with CAAD are eligible for carotid revascularization has been a clinical challenge for many years. The 2017 European Society of Cardiology (ESC)/ European Society for Vascular Surgery (ESVS) guidelines indicate that asymptomatic patients with carotid stenosis of $>60 \%$ (if life expectancy is $>5$ years, favourable anatomy and high risk of stroke) or symptomatic patients with carotid stenosis of $>50 \%$ are potential candidates for vascular surgery (-Fig. 1). ${ }^{26}$

Invasive treatments for CAAD include carotid endarterectomy (CEA) and carotid artery stenting (CAS). In a retrospective single-centre study of consecutive patients eligible for CEA $(n=1,118)$ or CAS $(n=1,084)$, there was no difference between the CAS and CEA groups in their 5-year combined risk of stroke or death within 30 days or ipsilateral stroke after the procedure (CAS, 3.7\%; CEA, 4.7\%). ${ }^{30}$ The Carotid Revascularization Endarterectomy versus Stenting Trial (CREST) randomized 2,502 asymptomatic and symptomatic patients to undergo CEA or CAS. ${ }^{31}$ The 4-year rate of stroke or death was 6.4\% with CAS and 4.7\% with CEA (hazard ratio [HR], 1.50; $p=0.03$ ). However, this difference was mainly driven by the rate of ipsilateral stroke in the peri-procedural period. ${ }^{31}$ Furthermore, an increased risk of peri-procedural MI was found in patients treated with CEA ( $2.3 \%$ vs. $1.1 \%$ of CAS, $p=0.03) .{ }^{28}$ Based on these findings, the decision for CEA or CAS should be individualized, taking into consideration each patient's characteristics and surgery risk. ${ }^{32}$ Moreover, CEA should be considered for patients with a life-expectancy of more than 3 to 5 years and with the following characteristics: (1) asymptomatic men $<80$ years with stenosis $>60 \%$; (2) symptomatic women with stenosis of 70 to $99 \%$ within 2 weeks of their last ischaemic event; (3) symptomatic men with stenosis of 50 to

Table 1 Risk of cardiovascular and cerebrovascular events associated with the presence of CAAD

\begin{tabular}{|c|c|c|c|c|}
\hline Disease/condition & Endpoint & $\begin{array}{l}\text { Study } \\
\text { sample } \\
\text { size }\end{array}$ & Measure of association & Ref. \\
\hline Atrial fibrillation & $\begin{array}{l}\text { Ischaemic } \\
\text { stroke }\end{array}$ & 724 & $\begin{array}{l}\text { cIMT continuous per } 1 \text { SD: HR } 1.23,95 \% \mathrm{Cl}, 1.04-1.46, p=0.02 \\
\text { Carotid plaque: HR 1.56, } 95 \% \mathrm{Cl}, 1.00-2.45, p=0.100\end{array}$ & 52 \\
\hline $\begin{array}{l}\text { Elderly } \\
(\geq 65 \mathrm{y})\end{array}$ & $\mathrm{CHD}$ & 5,895 & $\begin{array}{l}\text { Plaques at } 1 \text { site: } \\
\mathrm{HR}, 1.5,95 \% \mathrm{Cl}, 1.0-2.2 \\
\text { Plaques at } \geq 2 \text { sites: } \\
\mathrm{HR}, 2.2,95 \% \mathrm{Cl} 1.6-3.1 ; p<0.001\end{array}$ & 66 \\
\hline \multirow[t]{3}{*}{ Diabetes } & MACE & 259 & $\begin{array}{l}\text { Carotid plaque: } \\
\mathrm{HR}, 5.10,95 \% \mathrm{Cl}, 1.37-19.0 ; p=0.02\end{array}$ & 67 \\
\hline & CVD & 3,263 & $\begin{array}{l}\text { Common carotid max IMT (per } 0.1 \mathrm{~mm} \text { ): } \\
\mathrm{HR}, 1.08,95 \% \mathrm{Cl} 1.06-1.11 ; p<0.001\end{array}$ & 68 \\
\hline & MACE & 581 & $\begin{array}{l}\text { Heterogeneous plaque: } \mathrm{HR}, 3.10,95 \% \mathrm{Cl}, 2.09-4.23 \\
\text { Echogenic plaque: } \mathrm{HR}, 3.71,95 \% \mathrm{Cl} \\
2.09-5.59\end{array}$ & 69 \\
\hline Hypertension & Stroke & 356 & Plaque relative risk, $3.86 ; p=0.002$ & 70 \\
\hline $\begin{array}{l}\text { Peripheral artery } \\
\text { disease }\end{array}$ & $\begin{array}{l}\text { Coronary } \\
\text { events }\end{array}$ & 3,561 & Carotid atherosclerosis ${ }^{\mathrm{a}}: \mathrm{HR}, 1.37(95 \% \mathrm{Cl}, 1.17-1.60), p<0.0001$ & 71 \\
\hline $\begin{array}{l}\text { Coronary artery } \\
\text { disease }\end{array}$ & $\begin{array}{l}\text { Coronary } \\
\text { events }\end{array}$ & 12,982 & Carotid atherosclerosis $^{\mathrm{a}}: \mathrm{HR}, 1.25(95 \% \mathrm{Cl}, 1.16-1.35), p<0.0001$ & 71 \\
\hline $\begin{array}{l}\text { Cardiovascular } \\
\text { surgery }\end{array}$ & $\begin{array}{l}\text { Peri-operative } \\
\text { stroke }\end{array}$ & 1,059 & Carotid stenosis: OR, $4.68(95 \% \mathrm{Cl}, 1.62-13.47, p=0.001)$ & 72 \\
\hline SAVR & $\begin{array}{l}\text { Peri-operative } \\
\text { stroke }\end{array}$ & 50,979 & Carotid stenosis: OR, $1.8,95 \% \mathrm{Cl}, 1.1-2.8, p=0.009$ & 73 \\
\hline
\end{tabular}

Abbreviations: CAAD, carotid atherosclerotic artery disease; CHD, coronary heart disease; $\mathrm{Cl}$, confidence interval; CVD, cardiovascular disease; HR, hazard ratio; IMT, intima-media thickness; MACE, major adverse cardiovascular events; OR, odds ratio; SAVR, surgical aortic valve replacement; SD, standard deviation.

${ }^{a}$ Evidence of $\geq 1$ carotid plaque, asymptomatic carotid stenosis $\geq 70 \%$ and history of carotid revascularization. 

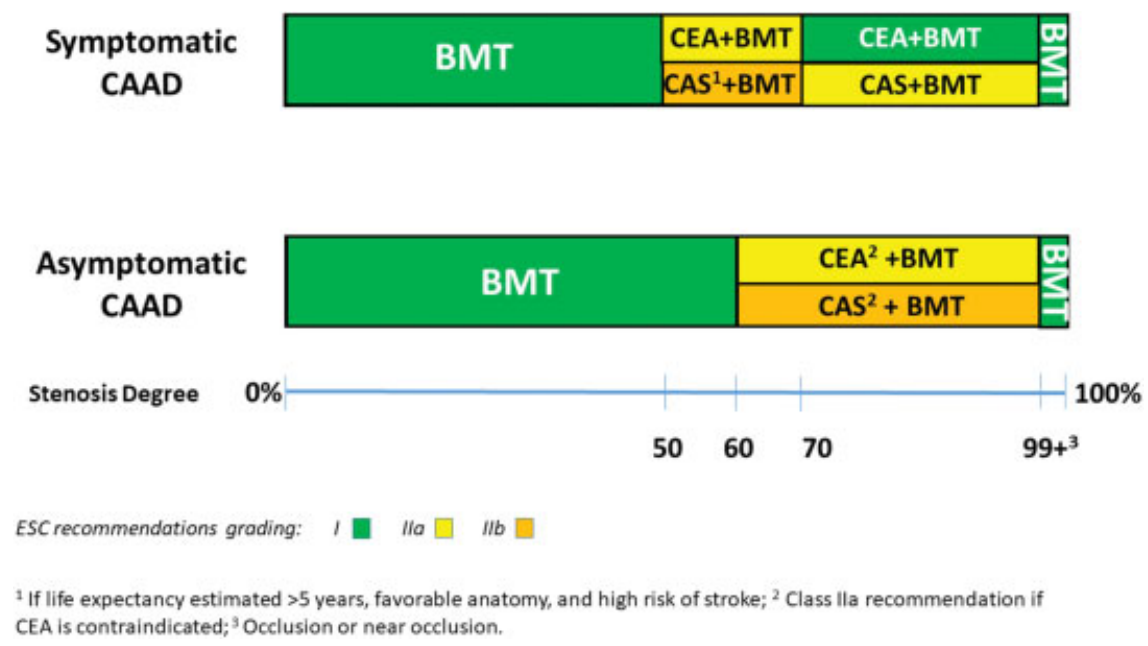

Fig. 1 Summary of recommendations for the management of patients with carotid atherosclerotic artery disease (CAAD). BMT, best medical therapy; CAAD, carotid artery atherosclerotic disease; CAS, carotid artery stenting; CEA, carotid endarterectomy.

$69 \%$ within 2 weeks of their last ischaemic event; and (4) symptomatic men with stenosis of 70 to $99 \%$ and without nearocclusion within 12 weeks from their last ischaemic event. ${ }^{33}$ Conversely, CAS should be considered in patients with restenosis after prior CEA, or with high risk of peri-operative complications, such as in patients with previous neck surgery or cranial nerve injury. ${ }^{29}$ Furthermore, a recent meta-analysis suggested that for patients with asymptomatic CAAD, CEA is preferred over CAS, owing to the increased risk for periprocedural stroke or death associated with CAS. ${ }^{34}$

According to the 2017 ESC/ESVS guidelines, patients with asymptomatic CAAD and stenosis of $<60 \%$, or symptomatic patients with carotid stenosis of $<50 \%$, gain no benefit from revascularization compared with medical therapy ( - Fig. 1). ${ }^{26}$ This recommendation is confirmed in a recent Cochrane review reporting that in symptomatic patients with $<30 \%$ stenosis, CEA increased the 5-year risk of ipsilateral ischaemic stroke and had no effect in those with 30 to $49 \%$ stenosis. $^{35}$

Therefore, all these asymptomatic patients' categories should be considered for medical therapy to manage atherosclerotic risk factors and reduce atherosclerotic burden and its complications. Lifestyle interventions are the first-line approach including smoking cessation, regular physical activity, weight loss to achieve a normal body mass index and healthy diet (i.e. Mediterranean diet) ${ }^{9,36}$ Moreover, tight glycaemic control, regular blood pressure monitoring and low levels of low-density lipoprotein cholesterol and triglycerides should always be a goal for these patients. ${ }^{9}$

The Carotid Revascularization Endarterectomy versus Stent Trial (CREST-2) is on-going and will randomize patients with asymptomatic carotid stenosis to medical therapy alone or with the addition of CEA or CAS. ${ }^{37}$

\section{Treatment}

The first medical approach to a patient with CAAD relies on the management of associated CV risk factors. Lifestyle interventions including weight loss, healthy diet, smoking cessation, physical activity, adequate blood pressure monitoring and tight glycaemic control should always be obtained in patients with CAAD (-Table 2). In particular, lipid-lowering therapy with statins should always be considered in these patients. ${ }^{29}$

In addition to lifestyle interventions and management of atherosclerotic risk factors, anti-platelet and anticoagulant drugs represent the mainstay of anti-thrombotic therapy in patients with CAAD.

\section{Anti-Platelet Drugs}

The rationale for the use of anti-platelet drugs in patients with carotid stenosis is based on the key role of platelets in the onset of acute thrombotic occlusion. ${ }^{38}$ Interventional trials with aspirin or thienopyridines showed a significant reduction in CV events in patients with or at risk for CV disease. In particular, a $12 \%$ reduction of serious adverse events in primary prevention trials (HR, 0.88 ; $95 \%$ confidence interval [CI], $0.82-0.94 ; p=0.0001)$ versus controls and a $19 \%$ in secondary prevention trials (HR, $0.81 ; 95 \% \mathrm{CI}, 0.75-0.87$; $p<0.00001$ ) versus controls was reported. ${ }^{39}$ A summary of different guidelines recommendations on the use of antiplatelet drugs in patients with CAAD is provided in - Table 2.

Asymptomatic CAAD: In patients with asymptomatic carotid artery stenosis, there is only weak evidence for the use of anti-platelet agents in primary prevention of CV events. In 372 patients with asymptomatic carotid stenosis of $\geq 50 \%$ followed up for 2 years and randomized to receive placebo or aspirin $325 \mathrm{mg} /$ day, there was no significant difference in the rate of ischaemic events between the two groups (11.0\% vs. $12.3 \%) .{ }^{40}$ Current guidelines generally recommend single anti-platelet therapy (commonly low-dose aspirin) in patients with asymptomatic CAAD, especially when the bleeding risk is low (-Table 2). ${ }^{26}$

Symptomatic CAAD: A recent meta-analysis including 15,778 participants from 12 trials of aspirin versus control for the secondary prevention of stroke, showed that aspirin reduced the 6 -week risk of recurrent ischaemic stroke by $60 \%$ 
Table 2 Management of patients with symptomatic and asymptomatic CAAD

\begin{tabular}{|c|c|c|}
\hline Intervention/drug & $\begin{array}{l}\text { Asymptomatic CAAD } \\
\text { ( } \geq 60 \% \text { stenosis) }\end{array}$ & $\begin{array}{l}\text { Symptomatic CAAD } \\
\text { ( } \geq 50 \% \text { stenosis)/Vascular } \\
\text { surgery (CEA/CAS) }\end{array}$ \\
\hline \multicolumn{3}{|l|}{ Lifestyle interventions $^{36}$} \\
\hline $\begin{array}{l}\text { Weight loss (to BMI }<24 \mathrm{~kg} / \mathrm{m}^{2} \text { ) } \\
\text { Healthy diet (i.e. Med-Diet) } \\
\text { Smoking cessation } \\
\text { Physical activity ( } 150 \mathrm{~min} / \mathrm{wk} \text { of } \\
\text { moderate aerobic or } 75 \mathrm{~min} / \mathrm{wk} \\
\text { of vigorous aerobic activity) }\end{array}$ & Always & Always \\
\hline \multicolumn{3}{|l|}{ Control of atherosclerotic risk factors } \\
\hline $\begin{array}{l}\text { Blood pressure }<140 / 85 \mathrm{~mm} \mathrm{Hg} \\
\text { Tight glycaemic control } \\
\text { LDL cholesterol target according } \\
\text { to cardiovascular risk }\end{array}$ & Always & Always \\
\hline \multicolumn{3}{|l|}{ Anti-thrombotic therapy } \\
\hline \multicolumn{3}{|l|}{ Anti-platelet } \\
\hline $2017 \mathrm{ESC} / \mathrm{ESVS}^{26}$ & $\begin{array}{l}\text { ASA } 75-100 \mathrm{mg} \text { once daily or } \\
\text { clopidogrel } 75 \mathrm{mg} \text { once daily } \\
\text { at the exception of patient at } \\
\text { very high bleeding risk (IlaC) }\end{array}$ & $\begin{array}{l}\text { ASA } 75-100 \mathrm{mg} \text { once daily or } \\
\text { clopidogrel } 75 \mathrm{mg} \text { once daily (IA) } \\
\text { DAPT for at least } 1 \text { month after CAS (IA) }\end{array}$ \\
\hline $2012 \mathrm{ACCP}^{74}$ & $\begin{array}{l}\text { ASA } 75-100 \mathrm{mg} \text { once } \\
\text { daily (IIB) }\end{array}$ & $\begin{array}{l}\text { Clopidogrel } 75 \mathrm{mg} \text { once daily or } \\
\text { ASA-ERD } 25 / 200 \mathrm{mg} \text { twice daily or } \\
\text { ASA } 75-100 \mathrm{mg} \text { once daily (IA) }\end{array}$ \\
\hline $2011 \mathrm{AHA}^{75}$ & ASA 75-325 mg once daily ${ }^{a}$ & $\begin{array}{l}\text { ASA } 75-325 \mathrm{mg} \text { once daily or } \\
\text { clopidogrel } 75 \mathrm{mg} \text { once daily, or the } \\
\text { ASA-ERD } 25 / 200 \mathrm{mg} \text { twice daily (IB) } \\
\text { ASA-ERD (25/200 mg twice daily) } \\
\text { preferred over ASA+ clopidogrel (IB) }\end{array}$ \\
\hline \multicolumn{3}{|l|}{ Anticoagulants } \\
\hline Anticoagulant alone & \multicolumn{2}{|l|}{ Not recommended ${ }^{\mathrm{C}}$} \\
\hline ASA + rivaroxaban $2.5 \mathrm{mg}$ twice daily & \multicolumn{2}{|l|}{ Selected patients $^{\mathrm{d}}$} \\
\hline $\begin{array}{l}\text { Anti-platelet }+ \text { standard dose } \\
\text { oral anticoagulant }\end{array}$ & No evidence & No evidence \\
\hline
\end{tabular}

Abbreviations: ACCP, American College of Clinical Pharmacy; AHA, American Heart Association; ASA, aspirin; BMI, body mass index; CAAD, carotid atherosclerotic artery disease; CAS, carotid artery stenting; CEA, carotid endarterectomy; DAPT, dual anti-platelet therapy; ERD, extended-release dipyridamole; ESC, European Society of Cardiology; ESVS, European Society for Vascular Surgery; LDL, low-density lipoprotein; PAD, peripheral artery disease. ${ }^{a}$ Obstructive or non-obstructive atherosclerosis involving extracranial carotid and/or vertebral arteries for prevention of myocardial infarction. No establish benefit for stroke prevention.

bobstructive or non-obstructive extracranial carotid or vertebral atherosclerosis who have sustained an ischaemic stroke.

I In absence of other indications for anticoagulation (i.e. atrial fibrillation, mechanical prosthetic valves, recurrent venous thromboembolism).

${ }^{d}$ In the COMPASS trial, carotid disease included both asymptomatic CAAD and patients with previous revascularization. Low-dose rivaroxaban + ASA were maximally effective in patients with 'symptomatic PAD' defined as the co-existence of symptomatic peripheral artery disease of lower extremities and carotid artery disease.

and the risk of disabling or fatal ischaemic stroke by $70 \%{ }^{41}$ The use of aspirin was also associated with less severe cerebrovascular events. ${ }^{41}$ Thus, in symptomatic carotid stenosis, the current European guidelines recommend longterm single anti-platelet therapy (grade IA). ${ }^{26}$

Also, the use of dual anti-platelet therapy (DAPT) has been investigated in symptomatic CAAD in the Clopidogrel and Aspirin for Reduction of Emboli in Symptomatic Carotid Stenosis trial showing that, in subjects with recently symptomatic $\geq 50 \%$ carotid stenosis, combination therapy with clopidogrel and aspirin was more effective than aspirin alone in reducing asymptomatic embolization (relative risk reduction,
39.8\%; 95\% CI, 13.8-58.0; $p=0.0046) .{ }^{42}$ Similar results were observed in the clopidogrel plus aspirin for infarction reduction in acute stroke or transient ischaemic attack patients with large artery stenosis and micro-embolic signals (CLAIR) study (relative risk reduction, $42.4 \%$; $95 \% \mathrm{CI}$, 4.6-65.2; $p=0.025$ ). ${ }^{43}$

However, current guidelines do not support the use of DAPT in patients with symptomatic CAAD, indicating longterm monotherapy with aspirin or clopidogrel or aspirin extended-release dipyridamole as the most appropriate treatment for these patients ( $\mathbf{- T a b l e ~} \mathbf{2}$ ).

$C A A D$ patients undergoing revascularization: In patients undergoing invasive carotid treatment (CEA/CAS), DAPT with 
aspirin and clopidogrel is currently recommended for $\geq 1$ month after CAS (grade IB), to avoid early complications after the procedure. ${ }^{26} \mathrm{~A}$ recent study including 28,683 CEA procedures, showed that the use of pre-operative DAPT was associated with a $39 \%$ risk reduction in neurologic events compared with aspirin alone (odds ratio [OR], $0.61 ; 95 \% \mathrm{CI}$, $0.43-0.87 ; p=0.007$ ), but also incurred a significantly increased risk of re-operation for bleeding after CEA (OR, $1.71 ; 95 \% \mathrm{CI}, 1.20-2.42 ; p=0.003) .{ }^{44}$

By contrast, DAPT was related to increased all-cause mortality in 471 patients with asymptomatic CAAD undergoing carotid intervention ( $47 \%$ vs. $40 \% ; p=0.05$ compared with aspirin alone), especially in patients aged $\geq 75$ years ( $82 \%$ vs. $56 \% ; p=0.001$ compared with aspirin alone). ${ }^{45}$ Conversely, no effect was noted in patients with symptomatic CAAD (38\% vs. $39 \% ; p=0.53$ ). ${ }^{45}$

Furthermore, there is no firm evidence on the optimal duration of DAPT after carotid revascularization. In Asymptomatic Carotid Surgery Trial-2, 86\% of centres prescribed DAPT post-operatively after CAS with a mean duration of 3 months (range, 1-12), compared with 9\% of centres prescribing long-term DAPT. Moreover, in patients who underwent CEA, $24 \%$ of centres prescribed DAPT post-operatively with a mean duration of 3 months (range, 1-5) and 10\% prescribed long-term DAPT. ${ }^{46}$

Another strategy was tested in the ARMYDA-9 CAROTID (Clopidogrel and Atorvastatin Treatment During Carotid Artery Stenting) study, which showed that $600 \mathrm{mg}$ clopidogrel load and a short-term reload with high-dose atorvastatin $(80+40 \mathrm{mg})$ reduced 30-day ischaemic cerebral events as compared with clopidogrel $300 \mathrm{mg}$ in 156 patients undergoing carotid stenting (18\% vs. $35.9 \%$ in the $300-\mathrm{mg}$ group; $p=0.019)^{47}$

The use of DAPT is currently recommended only by ESC/ ESVS for at least 1 month after CAS procedure (-Table $\mathbf{2}$ ).

\section{Anticoagulants}

The value of anticoagulants in patients with CAAD and no other indication for anticoagulation is unclear. Several trials are evaluating the efficacy and safety of NOACs in combination with anti-platelet therapy in patients with vascular disease, including CAAD. ${ }^{48,49}$ The ${ }^{50}$ Cardiovascular Outcomes for
People Using Anticoagulation Strategies (COMPASS) trial investigated a new therapeutic approach combining lowdose rivaroxaban ( $2.5 \mathrm{mg}$ twice daily) with aspirin $(100 \mathrm{mg}$ once daily) in patients with stable artery disease $(n=27,395)$ showing a beneficial effects in terms of reduction of $\mathrm{CV}$ events in patients with coronary artery disease $\mathrm{s}^{51}(n=24,824$, HR, $0.74 ; 95 \% \mathrm{CI}, 0.65-0.86 ; p<0.0001)$ or $\mathrm{PAD}^{8}(n=7,470, \mathrm{HR}$, $0.72 ; 95 \% \mathrm{CI}, 0.57-0.90, p=0.0047$ ). The latter category included patients with previous carotid revascularization as well as those with asymptomatic CAAD stenosis of $\geq 50 \%{ }^{8}$ Patients with CAAD were randomized to low-dose rivaroxaban $2.5 \mathrm{mg}$ twice daily plus aspirin $(n=617)$, rivaroxaban alone $5 \mathrm{mg}$ twice daily $(n=622)$ or aspirin $100 \mathrm{mg}$ once daily $(n=680) .^{8}$ The results in this sub-group of patients were consistent with the overall results of the COMPASS trial and those with PAD. Specifically, patients with CAAD had a lower incidence of major adverse cardiovascular events (MACEs) treated with rivaroxaban $2.5 \mathrm{mg}$ twice daily plus aspirin compared with those treated with aspirin alone $(3.9 \%$ vs. $6.0 \%, p=0.07$ ), with a similar rate of bleeding events between the two groups. ${ }^{8}$ Furthermore, combination therapy reduced major adverse $\mathrm{CV}$ and limb events compared with aspirin alone in patients with CAAD (some of whom had concomitant PAD), with an increase in non-serious major bleeding (-Table 3 ).

Also in patients with AF, in whom CAAD is detected in up to $38 \%$ of cases, ${ }^{52-54}$ a post hoc analysis from the Rivaroxaban Once Daily Oral Direct Factor Xa Inhibition Compared with Vitamin K Antagonism for Prevention of Stroke and Embolism Trial in Atrial Fibrillation showed that patients with AF had a similar risk of thromboembolism whether or not they had carotid disease, and that rivaroxaban had similar safety and efficacy compared with warfarin in this sub-group of patients. ${ }^{55}$

Another issue is the impact of low-dose rivaroxaban plus aspirin in patients presenting with multi-bed vascular disease, such as PAD in combination with CAAD and/or coronary artery disease. A recent study including 155,647 patients showed that CAAD and PAD may frequently co-exist (> 60\% of patients), increasing the risk of death and limb amputation. ${ }^{56}$ Thus, the effect of low-dose rivaroxaban in this very high-risk sub-group of patients with PAD and CAAD (including both prior carotid revascularization or existent asymptomatic carotid artery stenosis) seems to be of particular

Table 3 High-risk peripheral artery disease sub-groups in the COMPASS trial

\begin{tabular}{|c|c|c|c|c|}
\hline & \multirow{2}{*}{$\begin{array}{l}\text { All patients } \\
\mathrm{N}\end{array}$} & \multicolumn{3}{|c|}{$\begin{array}{l}\text { Hazard ratio ( } 95 \% \text { confidence interval) } \\
\text { for low-dose rivaroxaban }+ \text { aspirin (vs. aspirin alone) }\end{array}$} \\
\hline & & MACE & MACE/MALE ${ }^{b}$ & Major bleeding \\
\hline LEAD ${ }^{a}$ by eligibility & 5,551 & $0.74(0.57-0.96)$ & $0.70(0.55-0.88)$ & $1.75(1.16-2.65)$ \\
\hline Carotid disease by eligibility $^{c}$ & 1,919 & $0.63(0.38-1.04)$ & $0.64(0.41-1.01)$ & $1.18(0.55-2.50)$ \\
\hline Total with carotid and concomitant LEAD & 840 & $0.43(0.20-0.92)$ & $0.58(0.31-1.08)$ & $0.78(0.25-2.48)$ \\
\hline
\end{tabular}

Abbreviations: ABI, ankle-brachial index; LEAD, lower-extremity artery disease; MACE, major adverse cardiovascular event; MALE, major adverse limb event.

${ }^{a}$ Defined as intermittent claudication with $\mathrm{ABI}<0.90$ or stenosis of $\geq 50 \%$; or previous aorta-femoral or lower extremity bypass surgery, percutaneous transluminal angioplasty of iliac or infra-inguinal arteries or limb or foot amputation for arterial vascular disease.

${ }^{b}$ Combined outcome of MACEs and MALEs including major amputation.

${ }^{c}$ Defined as previous carotid endarterectomy or stent or asymptomatic carotid artery stenosis of $\geq 50 \%$. 
interest as this combination reduced by $32 \%$ the risk of $\mathrm{CV}$ events including MACEs and major adverse limb events including major amputation in the recent COMPASS trial (-Table 3).

A still open issue is the combination of standard dose anticoagulant with single antiplatelet therapy or DAPT in patients with CAAD. This association has been tested in different populations of patients with CV disease with divergent results. A previous meta-analysis showed that the addition of a VKA oral anticoagulant (international normalized ratio range, $1.4-3.0$ ) to aspirin (325 $\mathrm{mg}$ ) increased major bleeding (OR, 2.13; 95\% CI, 1.27-3.57) and mortality (OR, $1.57 ; 95 \% \mathrm{CI}, 1.16-2.12$ ) in patients with PAD. ${ }^{57}$

In patients with recent coronary artery disease, the addition of aspirin to a NOAC reduced the incidence of MACEs (HR, 0.70; 95\% CI, 0.59-0.84), but increased clinically significant bleeding ( $\mathrm{HR}, 1.79 ; 95 \% \mathrm{CI}, 1.54-2.09){ }^{58}$ Furthermore, the addition of a NOAC to DAPT only modestly decreased the incidence of MACE (HR, 0.87; 95\% CI, 0.800.95 ), but the risk of bleeding was at least doubled (HR, 2.34; 95\% CI, 2.06-2.66). ${ }^{58}$

- Table 2 summarizes medical and anti-thrombotic treatment for patients with CAAD.

For patients with PAD/CAAD and an indication to receive long-term anticoagulation, such as those with $\mathrm{AF}$, mechanical prosthetic heart valves or recurrent venous thromboembolism, evidence for adding an anti-platelet therapy should be wisely considered for the risk of bleeding. After an endovascular revascularization procedure, aspirin or clopidogrel should be considered in addition to oral anticoagulant for the shortest needed time (i.e. 1 month), especially if the bleeding risk is high. ${ }^{26}$ In this regard, particular attention should be paid on Asian AF patients treated with VKAs, for whom the risk of intracranial haemorrhage is increased compared with nonAsian patients. ${ }^{59}$ Conversely, anticoagulant therapy with standard-dose NOACs was more effective and safer in Asians than in non-Asians when compared with warfarin. ${ }^{60}$

However, no specific data on the risk of bleeding in Asian patients with CAAD treated with anticoagulant therapy (with or without anti-platelet drugs) are available.

\section{Future Perspectives}

The data detailed in this review indicate that some areas of medical and anti-thrombotic therapy in the carotid stenosis setting are still undefined and should continue to be explored in future. A summary of the levels of evidence for surgical or medical intervention for patients with CAAD is reported in - Fig. 1.

Peri-procedural and long-term CV risks are both elevated despite current anti-thrombotic therapy. The duration of anti-platelet therapy in patients undergoing vascular surgery is also unclear, but single anti-platelet therapy generally is administered lifelong. The effect of combination therapy of aspirin plus low-dose rivaroxaban in this group of patients should be investigated given their different risk profile.

An important still open issue is the mechanism accounting for the beneficial 'vascular effect' of low-dose rivarox- aban in atherosclerotic patients. Rivaroxaban reduces thrombin generation and eventually platelet activation, but a direct factor Xa-mediated anti-platelet effect cannot be excluded. Thus, there is evidence that glycoprotein (GP) VI is crucial for platelet activation by collagen as documented by impaired platelet responsiveness in case of platelet GPVI depletion. ${ }^{61}$ Similarly, factor Xa directly activates GPVI and rivaroxaban $(1 \mu \mathrm{g} / \mathrm{mL})$ inhibits GPVI-mediated platelet activation. ${ }^{61,62}$ Recent data supported and extended this report showing that, upon interaction with GPVI, factor Xa activates platelets by up-regulating nicotinamide adenine dinucleotide phosphate oxidase (Nox2), an enzyme which plays a crucial role not only in the immune system but also in the thrombotic process. ${ }^{63-65}$ Furthermore, concentrations of rivaroxaban (25-100 ng/mL) amplified the aspirin's antiplatelet effect by inhibiting Nox2-mediated platelet oxidative stress and eventually formation of the eicosanoids thromboxane A2 and isoprostanes. ${ }^{63}$ Future investigations are required to determine if this effect occurs in vivo.

\section{Conclusion}

Patients with CAAD have an increased risk of ischaemic stroke and other CV events. The combination of aspirin plus low-dose rivaroxaban appears superior to aspirin alone in reducing CV death, MI and stroke. There is a need for further research in patients with CAAD to optimize CV outcomes with anti-thrombotic therapy.

Conflict of Interest

Rupert Bauersachs: Funding from Bayer, BMS, Boehringer Ingelheim, Daiichi-Sankyo and Pfizer for consulting work and speaker bureaus. He also provides research support, as a principal investigator, for Bayer, BMS, Boehringer, Daiichi-Sankyo, Leo Pharma and Portola Pharmaceuticals. John W Eikelboom: Grants and personal fees from Bayer, Boehringer Ingelheim, Bristol-Myers Squibb/Pfizer, Daiichi-Sankyo, Janssen, AstraZeneca, Eli Lilly, GlaxoSmithKline and Sanofi Aventis.

Victor Aboyans: Honoraria from Bayer, Bristol-Myers Squibb, Pfizer, Novartis, Merck and Sharp \& Dohme.

Sonia S. Anand: Personal fees from Bayer and Novartis. Sigrid Nikol: Consulting and function as presenter for Bayer, Daichii-Sankyo and Pfizer.

Manesh R. Patel: Advisory boards/consultant to Bayer, Janssen and AstraZeneca.

Jean-Francois Tanguay: In-kind and financial support for physician-initiated grants from Spartan Bioscience, Roche Diagnostics, Aggredyne and Eli Lilly Canada; has received institutional research funding from Abbott Vascular, Novartis, Bayer, Biosensors and AstraZeneca; and has received honoraria for speaker/consultation/advisory board service from Abbott Vascular, AstraZeneca, Bayer, Servier and Eli Lilly.

Eike Sebastian Debus: Personal fees from Bayer AG and institutional fees from Cook Ltd. and Vascutek.

Lucia Mazzolai: Personal fees from Bayer Health Care, Pfizer, Bristol-Myers Squibb and Daiichi-Sankyo. 
Peter Verhamme: Grants and honoraria from Bayer, Boehringer Ingelheim, Bristol-Myers Squibb, Daiichi-Sankyo, Pfizer, Sanofi and LEO Pharma.

Jackie Bosch, Jean-Baptiste Ricco and Francesco Violi: Advisory board fees from Bayer.

Daniele Pastori and Mark Nehler: None.

\section{References}

1 Bansilal S, Castellano JM, Fuster V. Global burden of CVD: focus on secondary prevention of cardiovascular disease. Int J Cardiol 2015;201(Suppl 1):S1-S7

2 Camm AJ, Lip GY, De Caterina R, et al; ESC Committee for Practice Guidelines (CPG). 2012 focused update of the ESC Guidelines for the management of atrial fibrillation: an update of the 2010 ESC Guidelines for the management of atrial fibrillation. Developed with the special contribution of the European Heart Rhythm Association. Eur Heart J 2012;33(21):2719-2747

3 Adams HP Jr, Bendixen BH, Kappelle LJ, et al. Classification of subtype of acute ischemic stroke. Definitions for use in a multicenter clinical trial. TOAST. Trial of Org 10172 in Acute Stroke Treatment. Stroke 1993;24(01):35-41

4 Investigators SPiAF. Stroke prevention in atrial fibrillation study. Final results. Circulation 1991;84(02):527-539

5 Ruff CT, Giugliano RP, Braunwald E, et al. Comparison of the efficacy and safety of new oral anticoagulants with warfarin in patients with atrial fibrillation: a meta-analysis of randomised trials. Lancet 2014;383(9921):955-962

6 Amarenco P, Bogousslavsky J, Caplan LR, Donnan GA, Hennerici MG. Classification of stroke subtypes. Cerebrovasc Dis 2009;27 (05):493-501

7 Niu PP, Guo ZN, Jin H, Xing YQ Yang Y. Antiplatelet regimens in the long-term secondary prevention of transient ischaemic attack and ischaemic stroke: an updated network meta-analysis. BM] Open 2016;6(03):e009013

8 Anand SS, Bosch J, Eikelboom JW, et al; COMPASS Investigators. Rivaroxaban with or without aspirin in patients with stable peripheral or carotid artery disease: an international, randomised, double-blind, placebo-controlled trial. Lancet 2018;391 (10117):219-229

9 Langhoff R. Carotid stenosis - basing treatment on individual patients' needs. Optimal medical therapy alone or accompanied by stenting or endarterectomy. Vasa 2018;47(01):7-16

10 Herder M, Johnsen SH, Arntzen KA, Mathiesen EB. Risk factors for progression of carotid intima-media thickness and total plaque area: a 13-year follow-up study: the Tromsø Study. Stroke 2012; 43(07):1818-1823

11 Violi F, Loffredo L, Carnevale R, Pignatelli P, Pastori D. Atherothrombosis and oxidative stress: mechanisms and management in elderly. Antioxid Redox Signal 2017;27(14):1083-1124

12 Mathiesen EB, Joakimsen O, Bønaa KH. Prevalence of and risk factors associated with carotid artery stenosis: the Tromsø Study. Cerebrovasc Dis 2001;12(01):44-51

13 Wang TJ, Nam BH, Wilson PW, et al. Association of C-reactive protein with carotid atherosclerosis in men and women: the Framingham Heart Study. Arterioscler Thromb Vasc Biol 2002; 22(10):1662-1667

14 O'Leary DH, Polak JF, Kronmal RA, et al; The CHS Collaborative Research Group. Distribution and correlates of sonographically detected carotid artery disease in the Cardiovascular Health Study. Stroke 1992;23(12):1752-1760

15 LeFevre M; U.S. Preventive Services Task Force. Screening for asymptomatic carotid artery stenosis: U.S. Preventive Services Task Force recommendation statement. Ann Intern Med 2014; 161(05):356-362
16 Brott TG, Halperin JL, Abbara S, et al; American College of Cardiology; American Stroke Association; American Association of Neurological Surgeons; American College of Radiology; American College of Radiology; Society of NeuroInterventional Surgery; Society for Vascular Medicine; Society for Vascular Surgery. 2011 ASA/ACCF/AHA/AANN/AANS/ACR/ASNR/CNS/ SAIP/SCAI/SIR/SNIS/SVM/SVS guideline on the management of patients with extracranial carotid and vertebral artery disease. A report of the American College of Cardiology Foundation/ American Heart Association Task Force on Practice Guidelines, and the American Stroke Association, American Association of Neuroscience Nurses, American Association of Neurological Surgeons, American College of Radiology, American Society of Neuroradiology, Congress of Neurological Surgeons, Society of Atherosclerosis Imaging and Prevention, Society for Cardiovascular Angiography and Interventions, Society of Interventional Radiology, Society of NeuroInterventional Surgery, Society for Vascular Medicine, and Society for Vascular Surgery. Circulation 2011;124(04):e54-e130

17 Meschia JF, Bushnell C, Boden-Albala B, et al; American Heart Association Stroke Council; Council on Cardiovascular and Stroke Nursing; Council on Clinical Cardiology; Council on Functional Genomics and Translational Biology; Council on Hypertension. Guidelines for the primary prevention of stroke: a statement for healthcare professionals from the American Heart Association/ American Stroke Association. Stroke 2014;45(12):3754-3832

18 de Weerd M, Greving JP, de Jong AW, Buskens E, Bots ML. Prevalence of asymptomatic carotid artery stenosis according to age and sex: systematic review and metaregression analysis. Stroke 2009;40(04):1105-1113

19 de Weerd M, Greving JP, Hedblad B, et al. Prediction of asymptomatic carotid artery stenosis in the general population: identification of high-risk groups. Stroke 2014;45(08):2366-2371

20 Piepoli MF, Hoes AW, Agewall S, et al; ESC Scientific Document Group. 2016 European Guidelines on cardiovascular disease prevention in clinical practice: the Sixth Joint Task Force of the European Society of Cardiology and Other Societies on Cardiovascular Disease Prevention in Clinical Practice (constituted by representatives of 10 societies and by invited experts). Developed with the special contribution of the European Association for Cardiovascular Prevention \& Rehabilitation (EACPR). Eur Heart J 2016;37(29):2315-2381

21 Paciaroni M, Bogousslavsky J. Antithrombotic therapy in carotid artery stenosis: an update. Eur Neurol 2015;73(1-2):51-56

22 Kwon H, Kim HK, Kwon SU, et al. Risk of major adverse cardiovascular events in subjects with asymptomatic mild carotid artery stenosis. Sci Rep 2018;8(01):4700

23 Chimowitz MI, Kokkinos J, Strong J, et al. The warfarin-aspirin symptomatic intracranial disease study. Neurology 1995;45(08): 1488-1493

24 García-Pastor A, Gil-Núñez A, Ramírez-Moreno JM, et al; Stroke Project of the Spanish Cerebrovascular Diseases Study Group. Early risk of recurrent stroke in patients with symptomatic carotid near-occlusion: results from CAOS, a multicenter registry study. Int J Stroke 2017;12(07):713-719

25 Johansson E, Cuadrado-Godia E, Hayden D, et al. Recurrent stroke in symptomatic carotid stenosis awaiting revascularization: a pooled analysis. Neurology 2016;86(06):498-504

26 Aboyans V, Ricco JB, Bartelink MEL, et al. ESC Guidelines on the diagnosis and treatment of peripheral arterial diseases, in collaboration with the European Society for Vascular Surgery (ESVS): document covering atherosclerotic disease of extracranial carotid and vertebral, mesenteric, renal, upper and lower extremity arteries. Endorsed by: the European Stroke Organization (ESO), The Task Force for the Diagnosis and Treatment of Peripheral Arterial Diseases of the European Society of Cardiology (ESC) and of the European Society for Vascular Surgery (ESVS). Eur Heart J 2018;39(09):763-781 
27 Pastori D, Pignatelli P, Sciacqua A, Perticone M, Violi F, Lip GYH Relationship of peripheral and coronary artery disease to cardiovascular events in patients with atrial fibrillation. Int J Cardiol 2018;255:69-73

28 Brott TG, Hobson RW II, Howard G, et al; CREST Investigators. Stenting versus endarterectomy for treatment of carotid-artery stenosis. N Engl J Med 2010;363(01):11-23

29 Meschia JF, Klaas JP, Brown RD Jr, Brott TG. Evaluation and management of atherosclerotic carotid stenosis. Mayo Clin Proc 2017;92(07):1144-1157

30 De Rango P, Parlani G, Verzini F, et al. Long-term prevention of stroke: a modern comparison of current carotid stenting and carotid endarterectomy. J Am Coll Cardiol 2011;57(06):664-671

31 Timaran $\mathrm{CH}$, Mantese VA, Malas $\mathrm{M}$, et al; CREST Investigators. Differential outcomes of carotid stenting and endarterectomy performed exclusively by vascular surgeons in the Carotid Revascularization Endarterectomy versus Stenting Trial (CREST). J Vasc Surg 2013;57(02):303-308

32 Safian RD. Asymptomatic carotid artery stenosis: revascularization. Prog Cardiovasc Dis 2017;59(06):591-600

33 Abbott AL, Paraskevas KI, Kakkos SK, et al. Systematic review of guidelines for the management of asymptomatic and symptomatic carotid stenosis. Stroke 2015;46(11):3288-3301

34 Moresoli P, Habib B, Reynier P, Secrest MH, Eisenberg MJ, Filion KB. Carotid stenting versus endarterectomy for asymptomatic carotid artery stenosis: a systematic review and meta-analysis. Stroke 2017;48(08):2150-2157

35 Orrapin S, Rerkasem K. Carotid endarterectomy for symptomatic carotid stenosis. Cochrane Database Syst Rev 2017;6:CD001081

36 Eckel RH, Jakicic JM, Ard JD, et al; American College of Cardiology/ American Heart Association Task Force on Practice Guidelines. 2013 AHA/ACC guideline on lifestyle management to reduce cardiovascular risk: a report of the American College of Cardiology/American Heart Association Task Force on Practice Guidelines. Circulation 2014;129(25, Suppl 2):S76-S99

37 Howard VJ, Meschia JF, Lal BK, et al; CREST-2 study investigators. Carotid revascularization and medical management for asymptomatic carotid stenosis: protocol of the CREST-2 clinical trials. Int J Stroke 2017;12(07):770-778

38 Freynhofer MK, Bruno V, Wojta J, Huber K. The role of platelets in athero-thrombotic events. Curr Pharm Des 2012;18(33):5197-5214

39 Baigent C, Blackwell L, Collins R, et al; Antithrombotic Trialists' (ATT) Collaboration. Aspirin in the primary and secondary prevention of vascular disease: collaborative meta-analysis of individual participant data from randomised trials. Lancet 2009;373 (9678):1849-1860

40 Côté R, Battista RN, Abrahamowicz M, Langlois Y, Bourque F, Mackey A; The Asymptomatic Cervical Bruit Study Group. Lack of effect of aspirin in asymptomatic patients with carotid bruits and substantial carotid narrowing. Ann Intern Med 1995;123(09): 649-655

41 Rothwell PM, Algra A, Chen Z, Diener HC, Norrving B, Mehta Z. Effects of aspirin on risk and severity of early recurrent stroke after transient ischaemic attack and ischaemic stroke: time-course analysis of randomised trials. Lancet 2016;388(10042):365-375

42 Markus HS, Droste DW, Kaps M, et al. Dual antiplatelet therapy with clopidogrel and aspirin in symptomatic carotid stenosis evaluated using Doppler embolic signal detection: the Clopidogrel and Aspirin for Reduction of Emboli in Symptomatic Carotid Stenosis (CARESS) trial. Circulation 2005;111(17):2233-2240

43 Wong KS, Chen C, Fu J, et al; CLAIR study investigators. Clopidogrel plus aspirin versus aspirin alone for reducing embolisation in patients with acute symptomatic cerebral or carotid artery stenosis (CLAIR study): a randomised, open-label, blinded-endpoint trial. Lancet Neurol 2010;9(05):489-497

44 Jones DW, Goodney PP, Conrad MF, et al. Dual antiplatelet therapy reduces stroke but increases bleeding at the time of carotid endarterectomy. J Vasc Surg 2016;63(05):1262-1270
45 Alcocer F, Novak Z, Combs BR, et al. Dual antiplatelet therapy (clopidogrel and aspirin) is associated with increased all-cause mortality after carotid revascularization for asymptomatic carotid disease. J Vasc Surg 2014;59(04):950-955

46 Huibers A, Halliday A, Bulbulia R, Coppi G, de Borst GJ; ACST-2 Collaborative Group. Antiplatelet Therapy in Carotid Artery Stenting and Carotid Endarterectomy in the Asymptomatic Carotid Surgery Trial-2. Eur J Vasc Endovasc Surg 2016;51(03):336-342

47 Patti G, Tomai F, Melfi R, et al. Strategies of clopidogrel load and atorvastatin reload to prevent ischemic cerebral events in patients undergoing protected carotid stenting. Results of the randomized ARMYDA-9 CAROTID (Clopidogrel and Atorvastatin Treatment During Carotid Artery Stenting) study. J Am Coll Cardiol 2013;61(13):1379-1387

48 Bauersachs R, Zannad F. Rivaroxaban: a new treatment paradigm in the setting of vascular protection? Thromb Haemost 2018;118 (Suppl 1):S12-S22

49 Shahid F, Pastori D, Violi F, et al. Prognostic and therapeutic implications of vascular disease in patients with atrial fibrillation. Pharmacol Res 2018;132:149-159

50 Eikelboom JW, Connolly SJ, Bosch J, et al; COMPASS Investigators. Rivaroxaban with or without aspirin in stable cardiovascular disease. N Engl J Med 2017;377(14):1319-1330

51 Connolly SJ, Eikelboom JW, Bosch J, et al; COMPASS investigators. Rivaroxaban with or without aspirin in patients with stable coronary artery disease: an international, randomised, doubleblind, placebo-controlled trial. Lancet 2018;391(10117):205-218

52 Bekwelem W, Jensen PN, Norby FL, et al. Carotid atherosclerosis and stroke in atrial fibrillation: the atherosclerosis risk in communities study. Stroke 2016;47(06):1643-1646

53 Basili S, Loffredo L, Pastori D, et al; in collaboration with ARAPACIS Study Investigators. Carotid plaque detection improves the predictive value of $\mathrm{CHA}_{2} \mathrm{DS}_{2}$-VASc score in patients with non-valvular atrial fibrillation: the ARAPACIS Study. Int J Cardiol 2017;231:143-149

54 Kanter MC, Tegeler CH, Pearce LA, et al. Carotid stenosis in patients with atrial fibrillation. Prevalence, risk factors, and relationship to stroke in the Stroke Prevention in Atrial Fibrillation Study. Arch Intern Med 1994;154(12):1372-1377

55 Kochar A, Hellkamp AS, Lokhnygina Y, et al. Efficacy and safety of rivaroxaban compared with warfarin in patients with carotid artery disease and nonvalvular atrial fibrillation: insights from the ROCKET AF trial. Clin Cardiol 2018;41(01):39-45

56 Arya S, Khakharia A, Binney ZO, et al. Association of statin dose with amputation and survival in patients with peripheral artery disease. Circulation 2018;137(14):1435-1446

57 Investigators W; WAVE Investigators. The effects of oral anticoagulants in patients with peripheral arterial disease: rationale, design, and baseline characteristics of the Warfarin and Antiplatelet Vascular Evaluation (WAVE) trial, including a metaanalysis of trials. Am Heart J 2006;151(01):1-9

58 Verheugt FW. Combined antiplatelet and novel oral anticoagulant therapy after acute coronary syndrome: is three a crowd? Eur Heart J 2013;34(22):1618-1620

59 Shen AY, Yao JF, Brar SS, Jorgensen MB, Chen W. Racial/ethnic differences in the risk of intracranial hemorrhage among patients with atrial fibrillation. J Am Coll Cardiol 2007;50(04):309-315

60 Lip GYH, Banerjee A, Boriani G, et al. Antithrombotic therapy for atrial fibrillation: CHEST guideline and expert panel report. Chest 2018;154(05):1121-1201

61 Al-Tamimi M, Grigoriadis G, Tran H, et al. Coagulation-induced shedding of platelet glycoprotein VI mediated by factor Xa. Blood 2011;117(14):3912-3920

62 Pignatelli P, Pastori D, Bartimoccia S, et al. Anti Xa oral anticoagulants inhibit in vivo platelet activation by modulating glycoprotein VI shedding. Pharmacol Res 2016;113(Pt A):484-489

63 Cammisotto V, Carnevale R, Nocella C, et al. Rivaroxaban enhances the antiplatelet activity of aspirin via inhibition of Nox2-mediated thromboxane A2 and isoprostane biosynthesis. In: Vascular 
Discovery: From Genes to Medicine 2018 Scientific Sessions (Formerly ATVB|PVD Scientific Sessions). Dallas, TX: American Heart Association (AHA); 2018

64 Violi F, Carnevale R, Loffredo L, Pignatelli P, Gallin JI. NADPH oxidase2 and atherothrombosis: insight from chronic granulomatous disease. Arterioscler Thromb Vasc Biol 2017;37(02):218-225

65 Violi F, Carnevale R, Pastori D, Pignatelli P. Antioxidant and antiplatelet effects of atorvastatin by Nox2 inhibition. Trends Cardiovasc Med 2014;24(04):142-148

66 Plichart M, Celermajer DS, Zureik M, et al. Carotid intima-media thickness in plaque-free site, carotid plaques and coronary heart disease risk prediction in older adults. The Three-City Study. Atherosclerosis 2011;219(02):917-924

67 Jeevarethinam A, Venuraju S, Dumo A, et al. Usefulness of carotid plaques as predictors of obstructive coronary artery disease and cardiovascular events in asymptomatic individuals with diabetes mellitus. Am J Cardiol 2018;121(08):910-916

68 Katakami N, Mita T, Gosho M, et al. Clinical utility of carotid ultrasonography in the prediction of cardiovascular events in patients with diabetes: a combined analysis of data obtained in five longitudinal studies. J Atheroscler Thromb 2018;25(10):1053-1066

69 Vigili de Kreutzenberg S, Fadini GP, Guzzinati S, et al. Carotid plaque calcification predicts future cardiovascular events in type 2 diabetes. Diabetes Care 2015;38(10):1937-1944

70 Kawai T, Ohishi M, Takeya Y, et al. Carotid plaque score and intima media thickness as predictors of stroke and mortality in hypertensive patients. Hypertens Res 2013;36(10):902-909

71 Sirimarco G, Amarenco P, Labreuche J, et al; REACH Registry Investigators. Carotid atherosclerosis and risk of subsequent coronary event in outpatients with atherothrombosis. Stroke 2013;44(02):373-379

72 Tsuda K, Shiiya N, Washiyama N, et al. Carotid stenosis with impaired brain flow reserve is associated with an increased risk of stroke in on-pump cardiovascular surgery. Interact Cardiovasc Thorac Surg 2018;27(01):75-80

73 Udesh R, Mehta A, Gleason T, Thirumala PD. Carotid artery disease and perioperative stroke risk after surgical aortic valve replacement: a nationwide inpatient sample analysis. J Clin Neurosci 2017;42:91-96

74 Alonso-Coello P, Bellmunt S, McGorrian C, et al. Antithrombotic therapy in peripheral artery disease: Antithrombotic Therapy and Prevention of Thrombosis, 9th ed: American College of Chest Physicians Evidence-Based Clinical Practice Guidelines. Chest 2012;141(2, Suppl):e669S-e690S

75 Brott TG, Halperin JL, Abbara S, et al. 2011 ASA/ACCF/AHA/AANN/ AANS/ACR/ASNR/CNS/SAIP/SCAI/SIR/SNIS/SVM/SVS guideline on the management of patients with extracranial carotid and vertebral artery disease: executive summary: a report of the American College of Cardiology Foundation/American Heart Association Task Force on Practice Guidelines, and the American Stroke Association, American Association of Neuroscience Nurses, American Association of Neurological Surgeons, American College of Radiology, American Society of Neuroradiology, Congress of Neurological Surgeons, Society of Atherosclerosis Imaging and Prevention, Society for Cardiovascular Angiography and Interventions, Society of Interventional Radiology, Society of NeuroInterventional Surgery, Society for Vascular Medicine, and Society for Vascular Surgery. J Am Coll Cardiol 2011;57(08):1002-1044 